\title{
O ensino da Língua Portuguesa nas escolas primárias paulistanas no início do século XX
}

\section{Resumo}

Estudaram-se algumas das dificuldades no ensino da Língua Portuguesa nas escolas elementares públicas e privadas italianas existentes na cidade de São Paulo nos anos iniciais do século XX. Os programas de ensino sempre contemplaram a Língua Portuguesa, priorizando a leitura e a escrita. O grande número de alunos estrangeiros e filhos de estrangeiros comprometia o ensino da língua nacional. Existia ênfase na coesão linguística da população, visando à construção da identidade nacional. As fontes de pesquisa foram compostas por documentos do acervo do Arquivo Público do Estado de São Paulo. Concluiu-se que a italianização do ensino era um risco à aprendizagem da Língua Portuguesa nas escolas elementares paulistanas.

Palavras-chave: Ensino primário - São Paulo; Língua Portuguesa Estudo e Ensino; História da Educação.

\section{Para citar este artigo:}

PRADO, Eliane Mimesse $O$ ensino da Língua Portuguesa nas escolas primárias paulistanas no início do século XX. Revista Linhas. Florianópolis, v. 16, n. 32, p. 315 - 336, set./dez. 2015.

\author{
Eliane Mimesse Prado \\ Doutora em Educação pela \\ Pontifícia Universidade Católica \\ de São Paulo - PUC/SP - Brasil \\ emimesse@bol.com.br
}




\title{
The teaching of Portuguese language in primary schools São Paulo in the early 2oth century
}

\begin{abstract}
This article focuses on some of the obstacles to teaching the Portuguese language in public and private Italian Elementary Schools in the city of São Paulo in the early 20th century. The curriculums of such schools always included the Portuguese language, prioritizing reading and writing. The large number of foreign students and children of foreign background compromised the teaching of the national language. There was emphasis on the linguistic cohesion of the population, with the purpose of forming a national identity. Documents from the Public Archive of the State of Sao Paulo were used as research sources. We concluded that such Italianization jeopardized the teaching and learning of the Portuguese language in Elementary Schools in the city of São Paulo.
\end{abstract}

Keywords: Elementary schools - São Paulo; Portuguese Language - Study and Teaching; History of Education. 


\section{Introdução}

Foram amplas as dificuldades ao ensino da Língua Portuguesa nos anos iniciais do século XX. A cidade de São Paulo estava repleta de habitantes estrangeiros. Os imigrantes fixaram suas residências em bairros específicos, onde poderiam recriar seus antigos cotidianos, aproximando-se dos habitantes com a mesma procedência de modo a instituírem bairros que representassem suas respectivas localidades. As escolas foram criadas a partir dessa distribuição geográfica na cidade. Sendo assim, existiam dois tipos de escolas elementares; as públicas, que aceitavam alunos de todo tipo de procedência, e as escolas privadas, que recebiam subsídios do governo italiano e priorizavam os alunos com origem peninsular.

Nesse ponto se estabeleceu um conflito entre as escolas elementares públicas e privadas italianas. As escolas públicas ensinavam seus alunos a lerem e escrevem em Língua Portuguesa e as escolas subsidiadas italianas ensinavam em Língua Italiana.

Nos programas de ensino das escolas elementares públicas sempre constou o ensino da Língua Portuguesa, especificando a leitura, a escrita e a gramática. Em algumas situações eram considerados também o ensino da História e da Geografia do Brasil, para que os professores dessas matérias nas escolas com grande número de alunos estrangeiros pudessem ensinar sobre as peculiaridades locais.

Para compor os dados coletados para este artigo serão utilizadas fontes primárias documentais que possibilitaram a descoberta de novas luzes à História e agregaram valor à narrativa desenvolvida. Deve-se sempre lembrar a importância da releitura e revisão de documentos conhecidos e que podem ser entendidos sob outros aspectos.

O estabelecimento das fontes solicita um gesto fundador, representado pela contribuição de um lugar, de um aparelho ou de técnicas. Primeiro indício deste deslocamento: não há trabalho que não tenha de utilizar de outra maneira os recursos conhecidos. Neste artigo, as fontes documentais já tiveram outras utilizações durante sua existência, mas com objetivos diferenciados. Sendo assim, não se trata apenas de fazer falar estes imensos setores adormecidos da documentação e dar voz a um silêncio. Significa transformar algo, que tinha sua posição e seu papel, em outra coisa com funções diferentes. Da mesma forma, conforme Certeau (2002, p. 82) “[...] um trabalho é 
científico quando opera uma redistribuição do espaço e consiste, primordialmente, em se dar um lugar, pelo estabelecimento das fontes - quer dizer, por uma ação instauradora e por técnicas transformadoras".

Foram utilizados os Annuarios de Ensino do Estado de São Paulo, e um dos periódicos em Língua Italiana que circulava na cidade de São Paulo na época, denominado Fanfulla. Porque eram vários os periódicos em língua italiana que circulam na cidade de São Paulo nos anos finais do século XIX e iniciais do XX. Destes periódicos voltados à comunidade peninsular optou-se pela análise do Fanfulla, principalmente por ter publicado um volume encadernado no ano de 1906, agregando as temáticas de interesse à população peninsular. Esse volume ressaltava a contribuição econômica e social dos peninsulares em terras brasileiras.

Na análise dessa documentação foi necessário ir para além das aparências, de tal modo a investigar-se a sociedade como um todo no período analisado. As fontes documentais podem ser encontradas em arquivos, bibliotecas e em departamentos vinculados aos órgãos públicos que mantenham a prática do arquivamento de documentos. Os arquivos são os responsáveis pela guarda e manutenção dos mais diversos documentos, por que:

[...] compõem o mundo do jogo técnico, um mundo onde se reencontra a complexidade, porém, triada e miniaturizada e, portanto, formalizável. Espaço preciso em todos os sentidos do termo; [...] o equivalente profissionalizado e escriturário daquilo que representam os jogos na experiência comum de todos os povos, quer dizer, das práticas através das quais cada sociedade explicita, miniaturiza, formaliza suas estratégias mais fundamentais, e representa-se assim, ela mesma, sem os riscos nem as responsabilidades de uma história a fazer. (CERTEAU, 2002, p. 82)

Os Annuarios do Ensino do Estado de São Paulo foram criados no ano de 1907 e passaram a circular no ano de 1908. Foram organizados em volumes encadernados e separados por anos. Sua criação teve como objetivos demonstrar a estatística escolar; apresentar e discutir novas metodologias e processos didáticos destinados ao aprimoramento da formação dos professores e abordar assuntos diversos que poderiam colaborar com a educação popular. 
Os volumes eram compostos por informações provenientes dos relatórios anuais, redigidos pelos inspetores das Delegacias Regionais de Ensino da Capital e do interior do estado de São Paulo. Esses relatórios, por sua vez, registravam as atividades escolares de suas localidades, como a frequência dos alunos, a estabilidade do corpo docente, a descrição dos estabelecimentos escolares, as despesas com materiais, os métodos de ensino, os proventos mensais dos professores, a organização das escolas privadas entre outras.

Uma comissão redigiu o primeiro Annuario de Ensino no ano de 1907. O grupo foi constituído por inspetores escolares do estado de São Paulo, que justificaram a criação desses volumes visando atender a necessidade de o governo ter um documento com informações seguras sobre a movimentação escolar do estado, e ainda apresentar um diagnóstico da realidade escolar da cidade de São Paulo e das cidades do interior. Os demais volumes analisados foram assinados pelo diretor da Instrução Pública que exercia o cargo no momento. O necessário ensino da Língua Portuguesa e a proliferação das escolas subsidiadas italianas na cidade de São Paulo foram temas constantes por mais de dez anos.

No volume especial do periódico Fanfulla, que aqui foi estudado, pode-se verificar o ufanismo em relação aos imigrantes italianos que viviam na cidade paulistana. $O$ periódico era considerado, conforme Toledo (2002, p. 345), como “[...] monárquico, republicano, anticlerical, ou o contrário dos três adjetivos citados, ou mesmo nada disso". Era um periódico conservador que, com vistas a enaltecer a população peninsular, publicou esse volume especial composto por artigos e imagens.

\section{A cidade de São Paulo e as escolas dos imigrantes}

O estado de São Paulo recebeu imigrantes das mais diferentes etnias, principalmente durante os anos da segunda metade do século XIX e início do XX. Esses imigrantes desembarcavam na cidade portuária de Santos e, rumavam de trem para a capital. Todos os imigrantes recém-chegados dirigiam-se para a Hospedaria dos Imigrantes, local de recepção e encaminhamento dos trabalhadores às localidades agrícolas no interior do estado. 
Deste modo, a cidade de São Paulo obteve um grande crescimento populacional, com os indivíduos que se fixavam na cidade e, também, porque muitas famílias saíram das fazendas de café - pelos mais diversos motivos, no interior do estado e se dirigiram para a capital em busca de novas possibilidades de trabalho nas indústrias e no comércio.

[...] uma evolução marcante na última década do século XIX, impulsionada especialmente pela entrada de imigrantes estrangeiros que começaram a se dirigir à capital atraídos pelas oportunidades apresentadas por um mercado de mão de obra em expansão e pela expectativa de ascensão social. [...] A parcela estrangeira da população representou mais da metade do crescimento demográfico [...], indicando até mesmo um potencial forte de europeização no meio urbano, visto que compunha a maior parte da força de trabalho empregada na indústria, nas ocupações que exigiam certo grau de especialização e no setor de serviços, passando a influenciar hábitos e costumes. (PEREIRA, 2010, p. 132)

Deve-se considerar também que a superprodução da safra de café no estado de São Paulo, ocorrida entre os anos de 1906 e 1907, colaborou com o deslocamento da população do interior para a cidade. A demasiada produção extrapolou a demanda mundial no consumo do produto, inviabilizando a criação de novos cafezais e, em decorrência disso, dispensou-se um bom número dos trabalhadores contribuindo sobremaneira com a oferta de mão de obra. Entre os anos de 1900 e 1915, expandiu-se na cidade de São Paulo o número de cotonifícios, moinhos de farinha de trigo, fábricas de chapéus, calçados, marcenarias e cerâmicas.

A capital do estado de São Paulo acabou impondo-se como centro político-administrativo, passando progressivamente a exercer a primazia no campo econômico, estabelecendo ligações eficientes pela concentração de negócios, de capital financeiro, comercial e industrial. Esse crescimento e diversificação econômica foram acompanhados de uma progressiva expansão espacial e demográfica da cidade, impulsionada pelo complexo exportador cafeeiro, num período que se estendeu de 1870 até a década de 1920, quando, efetivamente, começou a esboçar os contornos de metrópole. (PEREIRA, 2010, p. 20)

A cidade de São Paulo se inseriu em um contexto singular, transformou-se, segundo Biondi (2010, p. 24) “durante o século XX, na metrópole com o maior número de 
descendentes de italianos no mundo, caracterizando-se, no início de sua expansão, como a cidade industrial do Brasil, na qual a componente italiana era majoritária em todos os setores de trabalho".

Para a cidade de São Paulo, foram várias as pessoas vindas das mais diversas localidades do estado. Com esse crescimento da população urbana, era necessário que os próprios estrangeiros se organizassem, na tentativa de suprirem as lacunas que o governo local não conseguia preencher. Esse é um dos motivos para a existência das inúmeras escolas privadas italianas na cidade de São Paulo, nesse período. As escolas subsidiadas na cidade chegaram a atender sete mil alunos nos primeiros anos do século XX, como constam nos dados do Annuario do Ensino de 1909.

Os alunos que frequentavam as escolas elementares públicas, certamente eram moradores dos bairros nos quais estavam localizadas as escolas. Seguramente, muitas dessas crianças eram provenientes de outros países ou eram filhas de estrangeiros, nascidas no Brasil. Não se pode deixar de crer que foram vários os peninsulares que enviaram seus filhos para as escolas públicas na cidade de São Paulo, como foi constatado nas listas de chamada de algumas dessas escolas, apesar da existência concomitante de muitas escolas elementares privadas italianas.

Mas, com a chegada dos imigrantes na cidade de São Paulo, acompanhados de seus filhos em idade escolar, as vagas nas escolas públicas não comportavam tamanho contingente. Uma das soluções encontradas pelas famílias imigrantes mais abastadas foi a procura de escolas particulares brasileiras, que do mesmo modo não ofereciam vagas suficientes para seus filhos, o que deu margem à criação de muitas novas escolas italianas elementares privadas, mantidas pelo governo italiano ou por iniciativa da coletividade, como ocorria com as escolas das sociedades de mútuo socorro.

A abertura de estabelecimentos de ensino particulares pelos próprios conterrâneos, nos moldes das escolas italianas, foi uma solução muito bem aceita pelos peninsulares. Sendo que essas escolas visavam a alfabetização das crianças na língua pátria de seu país de origem. As escolas, segundo o periódico Fanfulla (1906, p. 797) mantinham um "curso elementar completo, uma ou duas com curso complementar e uma tentativa de ensino clássico inicial, a maior parte eram compostas por apenas uma 
sala". A abertura de escolas elementares privadas italianas na cidade de São Paulo seguia preceitos similares aos existentes na terra natal dos professores peninsulares.

Os inspetores escolares que visitavam as escolas elementares da Capital descreviam em seus relatórios as dificuldades de o governo brasileiro lidar com o número excessivo de escolas estrangeiras. O ponto crucial dos textos dos inspetores escolares era o da precariedade das escolas públicas de ensino elementar, contribuindo sobremaneira com o crescimento das escolas privadas.

Mas, as escolas italianas, de acordo com os relatórios dos inspetores escolares da Capital, representavam um risco à nação brasileira, porque formavam crianças brasileiras natas em cidadãos italianos. Essas escolas ainda contavam com professores e diretores peninsulares, como consta do Annuario do Ensino de 1910.

As soluções apontadas pelos inspetores escolares para reduzir a ameaça dessas escolas na Capital eram a possibilidade de o governo brasileiro tornar todas as escolas estrangeiras italianas "auxiliares na instrução do ensino, sujeitando-as, porém, a um regime uniforme de organização, e fiscalizando-as assiduamente em seu funcionamento" (SÃO PAULO, 1907, p. 396).

A periculosidade das muitas escolas italianas residia no fato de que ensinavam as crianças a amarem outro país, de modo que o baixo número de inspetores escolares impossibilitava a efetiva fiscalização. O recurso encontrado por um dos inspetores era de que o governo paulista fizesse a doação de materiais para o ensino, como livros de História e de Geografia do Brasil, e deste modo, instituísse que essas escolas contratassem professores brasileiros para o ensino de Língua Portuguesa, de História e de Geografia do Brasil. Cogitando-se a possibilidade desse governo encerrar as atividades das escolas italianas subsidiadas de ensino primário que não cumprissem com essas determinações.

Só na Capital funcionam presentemente cerca de cem estabelecimentos dessa natureza, com matricula superior a seis mil crianças. Resta saber si tais estabelecimentos, em que o português não é língua oficial, podem oferecer ao Estado reais vantagens como auxiliares do Governo na ministração do ensino. (SÃO PAULO, 1907, p. 396) 
$\mathrm{O}$ argumento apresentado por um dos inspetores, sugerindo o encerramento das atividades das escolas, não condizia com a realidade escolar de São Paulo naquele momento. O governo do Estado não possuía verbas suficientes para criar novas escolas, em um número suficiente que pudesse suprir a demanda das crianças italianas e filhas de italianos. O ponto central da questão ainda permanecia o mesmo desde o início das discussões dos inspetores escolares nos anos finais do século XIX: a minguada verba pública disponível ao ensino. Portanto, os estrangeiros - tendo em vista esse quadro desolador da instrução pública de São Paulo, passaram a abrir escolas elementares privadas.

\section{A Língua Portuguesa contribuindo para a construção da Nação}

O ensino da Língua Portuguesa nos estabelecimentos primários, públicos ou privados no estado de São Paulo - salvo os estabelecimentos exclusivamente de idiomas -, era obrigatório desde a promulgação de uma lei no ano de 1896. Essa lei visava principalmente as escolas estrangeiras, criadas e frequentadas pela população imigrante. Mas, ela não foi prontamente cumprida, facilitando a manutenção do ensino no idioma no qual o professor tivesse maior conhecimento.

O embate educacional existente no Brasil, nos anos finais do século XIX e iniciais do século XX, levou os legisladores e educadores a preocuparem-se com a organização das escolas elementares, em decorrência dos altos índices de analfabetismo. O legislador Barbosa (1999), deixou clara sua “devoção à causa do ensino popular”. A importância do ensino não estava apenas nas reformas, mas na necessidade de colocá-las em prática, de modo a "reformar os costumes". Em discurso, frisou a necessidade de instrução do povo e a premente ação na sua educação, como meio saneador para a realização das “aspirações democráticas”.

A instrução do povo, ao mesmo tempo em que o civiliza e o melhora, tem especialmente em mira habilitá-lo a se governar a si mesmo, nomeando periodicamente, no Município, no Estado, na União, o chefe do poder Executivo e a Legislatura. (...) Este se ressentiria de imperdoável omissão, se eu vos não dissesse como compreendo os meios mais próximos de acudir. Com a urgência precisa, a uma das nossas maiores aspirações democráticas, realizando seriamente. (BARBOSA, 1999, p. 328) 
Tem-se de considerar que, nessa época, a população brasileira era constituída principalmente por imigrantes das mais variadas etnias; ex-escravos, índios e brasileiros. Levando-se em conta a população como um todo, poucos eram os sujeitos alfabetizados na Língua Portuguesa. Nesse momento, iniciou-se um conflito tácito na cidade de São Paulo, entre as escolas italianas privadas e as escolas públicas brasileiras. De um lado, as escolas italianas que recebiam subsídios do governo italiano para manterem o ensino em Língua Italiana e o sentimento de amor à nação; de outro lado, as escolas brasileiras que deveriam educar suas crianças em Língua Portuguesa, esse país por sua vez, ainda buscava uma identidade, em função do grande número de imigrantes que o habitavam.

Nesse ínterim, a legislação brasileira tornou obrigatório o ensino da matéria de Língua Portuguesa, mas a lei que a regulamentava não era plenamente cumprida, de modo que, as escolas subsidiadas italianas tinham a possibilidade de ensinarem todos os seus conteúdos em Língua Italiana, seguindo os programas de ensino das escolas italianas e, deste modo, ensinarem - quando possível - a Língua Portuguesa como um idioma estrangeiro.

Segundo um dos inspetores escolares da cidade de São Paulo, a lei que tratava da obrigatoriedade do ensino da matéria de Língua Portuguesa, no ano de 1907, ainda não estava regulamentada. Deste modo, este inspetor escolar defendia a necessidade de regulamentação o mais breve possível para garantir a implantação do ideal de nacionalização, porque nestas condições, nas quais esses estabelecimentos se encontravam: "[...] o inspetor escolar só pode averiguar se nessas escolas é ou não feito tal ensino. É claro que isso é insuficiente, o inspetor precisa conhecer se essas escolas estão nacionalizadas" (SÃO PAULO, 1907, p. 43).

Após uma inspeção feita no Instituto pelo inspetor escolar, ele reconheceu que o ensino da Língua Portuguesa era ensinado no Instituto italiano, conforme o programa vigente no Estado de São Paulo, o Governo concedeu ao Instituto Dante Alighieri um subsídio, deixando ao mesmo tempo ao professor-diretor um atestado oficial. (FANFULLA, 1906, p. 805, tradução nossa) 
Por outro lado, o governo italiano pretendia contribuir com a instrução da criança italiana ou filha de italianos, que vivia fora da Itália com o despacho de subsídios aos materiais didáticos e a manutenção das escolas privadas italianas. Esse incentivo era enviado a partir da Società Dante Alighieri, que em seus congressos debatia sobre a necessidade da manutenção da italianidade. Os relatórios dos inspetores escolares da capital apontavam para o crescimento das escolas subsidiadas italianas nos bairros operários existentes.

Não esqueçam os senhores representantes do município de que só no Braz (bairro operário da cidade de São Paulo) - a estatística ai está para afirmar com a clareza de seus algarismos - muito mais de 2 mil crianças, nascidas aqui, frequentam por falta de lugar nos estabelecimentos do governo, escolas que recebem subvenção do estrangeiro, escolas onde 0 nome do Brasil, da sua terra, é vagamente ouvido de quando em vez. (SÃO PAULO, 1907, p. 43)

O Diretor da Instrução Pública, no ano de 1913, escreveu um documento no qual reiterou e retomou a discussão sobre as escolas estrangeiras e a ausência no ensino das matérias de História brasileira, Geografia do Brasil e Língua Portuguesa. Alertou aos educadores sobre quais as medidas que deveriam ser tomadas rapidamente para que a italianização do ensino nas escolas elementares da capital não se expandisse e se enraizasse definitivamente na sociedade.

[...] imagine-se tal sistema de escolas, alastrada por todos os Estados do país, e em futuro não muito remoto e fatal a obliteração do sentimento patriótico, que mina e promove a grandeza das nações. Não se compreende uma lacuna dessas em escolas, cujos alunos, não obstante serem, na sua quase totalidade, filhos de estrangeiros, consideram-se, entretanto, como brasileiros natos. (SÃO PAULO, 1913, p. XXIII)

O documento do diretor da Instrução Pública reforçou a necessidade de um ensino que aprofundasse os assuntos sobre o Brasil. A História e a Geografia brasileiras que deveriam ser envaidecidas pelos professores, principalmente os das escolas elementares, por conviverem com as crianças que por várias razões não tendiam a continuar a frequentar a escola após a conclusão do curso elementar. Sendo assim, o professor teria 
o dever cívico de ensinar aos seus alunos sobre as grandezas do território brasileiro e seus ilustres personagens, para assim poderem ser nacionalizados.

Atendendo-se que os homens são a feitura de sua educação, que esperar de futuros cidadãos aos quais é um mistério o conhecimento dos nossos grandes homens, das nossas tradições, da nossa língua, da grandeza e pujança de nosso território, das nossas instituições, de todos esses fatos, enfim, que caracterizam a nossa nacionalidade? (SÃO PAULO, 1913, p. XXIII)

Ainda, segundo esse mesmo documento, escrito pelo diretor da Instrução Pública, era imprescindível a instituição de um regulamento que obrigasse o ensino dessas matérias nas escolas estrangeiras, principalmente as italianas, porque era dever do governo "amparar e proteger a infância contra os males que lhe podem advir da ausência de um ensino a que ela tem direito" (SÃO PAULO, 1913, p. XXIII). Na opinião deste diretor, o ensino teria de se relacionar ao meio social em que a criança vivia, para que ela fosse formada com os conhecimentos acerca de sua localidade, de sua cidade e, consequentemente, de seu país de nascimento. Esse diretor da Instrução Pública culpava os pais imigrantes que optavam pelas escolas subsidiadas italianas, e os professores, em sua grande maioria de origem peninsular, que trabalhavam nas escolas italianas por “imporem uma educação estrangeira às crianças, privando-as do conhecimento sobre o seu país de nascimento". Desta forma, essas crianças acabariam por receber uma “instrução alheia a tudo quanto se relaciona com o seu país, lhe apagam do coração todo o sentimento patriótico, Ihe roubam o sacrossanto direito de amar a Pátria, porque ela não poderá amar o que lhe é totalmente desconhecido" (SÃO PAULO, 1913, p. XXIII).

No ano de 1914, os documentos retomaram as discussões sobre a obrigatoriedade do ensino das matérias de Língua Portuguesa, História e Geografia do Brasil nas escolas subsidiadas privadas estrangeiras. Os comentários versavam sobre os professores estrangeiros que lecionavam as aulas nas escolas, e exatamente por sua condição de estrangeiros, não dominavam os conteúdos específicos dessas matérias para ensiná-los. Um dos documentos trazia novamente a defesa da regulamentação da lei que tornou 
obrigatório o ensino dessas matérias, mas como ainda não havia sido colocada em prática, as omissões continuavam a ocorrer.

Ministrado, no geral, por estrangeiros desconhecedores da nossa língua, é esta adulterada, deturpada em sua terminologia e sintaxe, de modo que pode ser tudo, menos português. Ha aqui na Capital, muitas, inúmeras escolas, onde não se fala uma palavra de português na transmissão do ensino, e não se trata de escolas de línguas, mas de escolas primarias, destinadas ao ensino da infância, parte integrante de nossa nacionalidade, pelo nascimento ou pela nacionalização, e que amanhã vai influir nos nossos destinos como cidadãos brasileiros. (SÃO PAULO, 1914, p. 20)

\section{Os programas de ensino}

As escolas elementares públicas da capital eram mantidas pelo governo do estado de São Paulo e as escolas que existiam na cidade no início do século XX, apresentavam deficiências no seu funcionamento. Podem-se listar os problemas por elas encontrados no seu desenvolvimento quanto ao espaço físico, aos materiais didáticos, à formação dos professores e à diversidade de métodos de ensino aplicados. Muitas foram as críticas recebidas por estes profissionais emanadas pelos inspetores escolares. Normalmente, o espaço físico destinado à escola era indevido, por ocupar um cômodo qualquer ou uma das salas de uma residência de família, neste caso, a família do professor. Um dos inspetores escolares apresentou uma solução para a situação:

[...] a primeira providencia que reclama a escola e se impõe, exigindo pronta execução, é a construção de casas escolares, de acordo com os preceitos da higiene pedagógica. [...] O ônus que pesa sobre os modestos vencimentos do professor com o estipendio dos alugueis do aposento escolar, o obriga naturalmente a reduzir ao mínimo tal despesa, procurando pequenas salas, imprestáveis sob todos os aspectos, com flagrante sacrifício dos preceitos higiênicos e menosprezo pelas regras pedagógicas. (SÃO PAULO, 1910, p. 50)

Outra apreciação era quanto à inexistência de móveis destinados especialmente a essas escolas; usavam-se bancos, caixotes de madeira, mesas improvisadas e cadeiras dos mais diversos tipos, muitas vezes cedidos pelos pais dos alunos. Em pesquisa desenvolvida em um núcleo colonial vêneto, Mimesse (2010) identificou, no final do 
século XIX, nos arredores da capital da cidade de São Paulo, que as escolas elementares femininas e masculinas eram muito precárias.

No ano de 1907, os documentos dos inspetores escolares apresentaram algumas considerações sobre as escolas elementares da cidade de São Paulo, criticando sua desagregação, porque "não formam partes integrantes de um todo harmônico, não podem ser consideradas como órgãos conexos de um aparelho, tendo uma função geral que seja como que a integração final de muitas funções especializadas" (SÃO PAULO, 1907, p. 15). Ainda no mesmo documento, um dos inspetores escolares discorreu sobre a falta de materiais para essas escolas, explicando o modo desigual como era distribuído e, acrescentou que na sua maioria, as escolas funcionavam somente com os livros de chamada. Seria necessária a distribuição uniforme em todas as escolas dos materiais para o ensino. A fim de que a opção dos pais em matricularem seus filhos nas escolas privadas italianas fosse paulatinamente reduzida, este quadro persistia em função do contraponto com as escolas públicas, o inspetor explicou que "[...], sobretudo as escolas italianas, são preferidas pelos pais. O governo italiano protege e auxilia as escolas que a colônia aqui mantém, ao passo que o Estado as abandona completamente" (SÃO PAULO, 1907, p. 15).

A discussão sobre a precariedade das escolas elementares e as censuras por elas acarretadas, começou a tomar maior espaço nos debates após a transferência da Corte Portuguesa ao Brasil, no início do século XIX. Desde a criação desta modalidade de escola muitas falhas foram constatadas e poucas delas sanadas. Um dos inspetores escolares registrou em seu texto considerações sobre a instabilidade dos professores das escolas elementares, porque esses professores assumiam as cadeiras nessas escolas para iniciarem a carreira. Mais do que

[...] cuidar de sua única e especial missão de ensinar e educar. Os pais não mandam os filhos a escola, porque já sabem que, durante o ano letivo, haverá na localidade dois ou três professores, no intervalo de cujas nomeações haverá férias forçadas de três, quatro ou mais meses, não se contando as licenças ocasionadas pelo desanimo dos professores. (SÃO PAULO, 1910, p. 107) 
Deste modo, as escolas elementares públicas não poderiam suprir a demanda de alunos em idade escolar na cidade de São Paulo; proporcionando, às escolas privadas italianas, expansão nos bairros operários da cidade. Mas, as escolas italianas, apesar de manterem o caráter de escolas privadas, recebiam subsídios e não apresentavam muitas diferenças quanto à estrutura física ou à organização escolar das escolas públicas.

As escolas privadas italianas eram criadas nas residências dos professores, que na maioria das vezes também eram seus diretores. As casas em que funcionavam as escolas subsidiadas, a princípio, eram alugadas. Essas casas-escolas tinham alguns cômodos separados para acomodar a família do professor e as salas de aulas. Os quartos maiores, com fácil acesso, tornavam-se parte das escolas masculinas e femininas. Cada escola ocupava apenas uma sala agregando alunos de idades e níveis de conhecimento diferentes, exatamente como ocorria nas escolas elementares públicas da capital. Alguns modelos de casas eram preferidos para a convivência comum; entre os familiares do professor e o funcionamento das escolas eram as casas com mais de um piso, e que contivessem um local aberto ao fundo para abrigar as crianças nas atividades físicas e recreativas. As casas assobradadas eram ideais para a instalação das escolas, de modo que os sexos ficavam separados, segundo os andares do edifício.

Geralmente, nas escolas italianas subsidiadas e nas públicas, o professor regia a escola masculina e sua esposa ou filhas regiam a escola feminina. Mas, com o passar dos tempos, essas escolas passaram a receber um maior número de alunos, fazendo com que seu proprietário buscasse outros edifícios para abrigá-las e contratasse novos professores, além de seus familiares próximos. Todos os funcionários dessas escolas, como foi constatado na documentação pesquisada até o momento, eram de origem peninsular ou eram filhos de peninsulares que tinham fluência no idioma da região de seus familiares.

Nesse sentido, a imposição no ensino da Língua Portuguesa era a cada dia, mais necessária. Apesar de todos os peninsulares moradores da cidade de São Paulo serem reconhecidos como italianos, eles viviam em bairros em que se identificavam regionalmente com os outros moradores, dando margem para o uso no cotidiano de outros idiomas. 
Nos anos iniciais do século XX existiam na cidade de São Paulo mais de 70 escolas privadas subsidiadas pelo governo italiano. Essas escolas deveriam seguir o programa de ensino instituído e praticado na Itália naquele momento. Além de manterem em seus programas o ensino da matéria de Língua Portuguesa, todas essas escolas ofereciam o curso de instrução primária elementar e algumas delas também mantinham cursos noturnos, aulas de exercícios ginásticos, cursos preparatórios para o ingresso no superior, cursos de trabalhos manuais, de línguas, entre outros.

As matérias que ensinavam deveriam prever o ensino da Língua Italiana, a necessidade de promover a consciência do idioma italiano a partir da experiência linguística, visando uma aprendizagem correta da utilização do idioma, e ainda desenvolver e manter o sentimento nacional. O programa de algumas das escolas subsidiadas italianas da cidade de São Paulo, conforme dados do Annuario do Ensino de 1907, era composto por: Leitura, Escrita, Religião, Caligrafia, Gramática, Geografia Física, História Nacional, Noções de Ciências Físicas e Naturais, Aritmética e Noções do Sistema Métrico Decimal.

Em nenhuma das escolas subsidiadas estudadas identificou-se o ensino das matérias de Língua Portuguesa, História ou de Geografia do Brasil, mesmo que, a partir do ano de 1904, existisse a imposição de novas regras ao ensino nas escolas estrangeiras, acompanhadas de ameaças de supervisão por parte dos inspetores escolares, como descrito por Salvetti (1995).

O programa de ensino debatido nos relatórios dos inspetores de ensino, no Annuario do Ensino de 1907, apontava para as matérias que deveriam servir de padrão às escolas elementares públicas: Leitura, Linguagem, Números, Caligrafia, Geografia, História Pátria, Animais, Plantas, Lições gerais, Desenho, Música, Trabalho manual e Ginástica. Esse programa de ensino das escolas da capital era similar ao programa adotado pelas escolas subsidiadas italianas, com poucas diferenças. Entre elas, identificou-se a omissão nas escolas subsidiadas do ensino da matéria de Língua Portuguesa.

Alguns dos inspetores escolares defendiam, em seus relatórios, a necessidade de redução dos conteúdos existentes nos programas de ensino das escolas elementares. 
Esses inspetores acreditavam que o acúmulo de matérias ofertadas interferia na frequência dos alunos, que desistiam de frequentar a escola logo após aprenderem a leitura e a escrita, não indo além dos três anos de permanência nos bancos escolares. A defesa desses inspetores era no sentido de se manterem nos programas de ensino apenas as "disciplinas de maior utilidade, como Leitura, Linguagem Oral, Escrita e Cálculo" (SÃO PAULO, 1908, p. 14).

O relatório de um dos inspetores escolares, constante no Annuario do Ensino do ano de 1908, ainda aponta que a preocupação das escolas elementares deveria ser o predomínio na linguagem. Esta deveria ser considerada o centro de todos os programas de ensino, em todos os níveis. Os exercícios deveriam ser dirigidos à aprendizagem das palavras e da escrita, e contribuírem com a expressão das ideias, com ordem, segurança e clareza. Em verdade, a defesa é para que se evitasse o excesso nas regras de gramática da Língua Portuguesa e o uso mais frequente do livro de leitura, que poderia ser usado como grande auxiliar na aprendizagem da linguagem porque, segundo o inspetor escolar, somente lendo e interpretando é que as crianças aprenderiam a falar bem e a elaborarem composições.

A Instrução Pública do estado de São Paulo passou por reformas após a proclamação da República, no ano de 1889. Foi implantada uma Reforma da Instrução Pública a partir da Lei 88 de 08 de setembro de 1892. No programa de ensino dessa Lei constavam: Moral Prática e Educação Cívica; Leitura e Princípios de Gramática, Escrita e Caligrafia; Noções de Geografia Geral e Cosmografia; Geografia do Brasil, especialmente de São Paulo; História do Brasil e Leitura sobre a vida dos grandes homens da História; Cálculo Aritmético sobre números inteiros e frações, Sistema Métrico Decimal, Noções de Geometria, especialmente nas suas aplicações à medição de superfície e volumes; Noções de Ciências Físicas, Químicas e Naturais nas suas mais simples aplicações, especialmente a higiene; Desenho a mão livre; Canto e Leitura de Música; Exercícios Ginásticos, Manuais e Militares, apropriados à idade e ao sexo. A inserção de Moral Prática, Cosmografia, História do Brasil e Exercícios Manuais e Militares era uma das formas de consolidar a formação do caráter e dos valores nos alunos das escolas elementares.

Para as escolas primárias esse conjunto de matérias revelava o sentido da educação popular propugnada pelos republicanos paulistas. Educar, mais que instruir, constituía a finalidade fundamental do ensino primário. Essa 
diferenciação sublinhada por vários educadores na época não era simples questão semântica. Ela reportava a uma clara concepção de ensino educar supunha um compromisso com a formação integral da criança que ia muito além da simples transmissão de informações fornecidas pela instrução, implicava, essencialmente, a formação do caráter mediante a aprendizagem da disciplina social, das virtudes morais e dos valores cívico-patrióticos necessários à formação do espírito da nacionalidade. (SOUZA, 2009, p. 83)

Os inspetores escolares fizeram várias críticas em seus relatórios sobre a amplitude do programa de ensino de 1892 e sobre as dificuldades dos professores em cumprirem todos os itens propostos nos conteúdos. Sendo assim, esse programa foi modificado no ano de 1904. O programa de ensino sofreu alterações ligeiras, podendo-se identificar pequenas reduções nos conteúdos a serem ensinados. O novo programa de ensino passou a priorizar: Moral e Educação Cívica; Leitura, Escrita; Cálculo; Noções de Ciências Físicas, Químicas e Naturais; Desenho; Canto e Música. Na prática, verificando os relatórios enviados pelos professores ao Diretor da Instrução Pública, eles priorizavam o ensino de Leitura, Escrita, Caligrafia e Aritmética, que eram consideradas as matérias fundamentais ao aprendizado das crianças. Algumas matérias enriqueceram o programa de ensino do final do século XIX, mas no século XX nem todas as matérias permaneceram nas salas de aulas. Quando a sala de aula era composta por alunos de diferentes etnias, filhos de imigrantes, ou mesmo estrangeiros, a prioridade dos professores era o ensino da Língua Portuguesa, Leitura, Escrita e Caligrafia. Os estudos da gramática da Língua Portuguesa somente eram ministrados aos alunos com maior conhecimento dos conteúdos.

O programa de ensino foi novamente revisto no ano de 1911 e previa o ensino das mesmas matérias, apenas era diferenciado pela profundidade e abrangência nos conteúdos: Leitura, Linguagem, Aritmética, História do Brasil, Geografia, Ciências Naturais (animais, plantas, lições gerais), Caligrafia, Desenho, Canto, Trabalho Manual e Ginástica. Os programas tendiam a enfatizar o ensino da Caligrafia, porque essa matéria era entendida como auxiliar ao ensino da Linguagem.

Na escola primária, a caligrafia constituiu atividade educativa que moldou comportamentos. Escrever com correção e letra legível 
(preferencialmente cursiva e com traçados elegantes) era demonstrar a posse de uma cultura erudita. [...] Grande ênfase foi dada à caligrafia concebida no mesmo sentido de escrita ou como arte de escrever bem. (SOUZA, 2009, p. 83)

\section{Considerações Finais}

Os programas de ensino aprovados e colocados em prática no estado de São Paulo, entre o final do século XIX e início do XX priorizavam o ensino de algumas matérias como a Língua Portuguesa, a História, a Geografia, a Instrução Moral e Cívica e os exercícios físicos. Essas matérias sempre visaram o desenvolvimento do sentimento de nacionalismo e de patriotismo nos alunos das escolas elementares e contribuiriam, deste modo, para a formação moral da população do estado de São Paulo, e ainda com a construção da identidade nacional.

Apesar da obrigatoriedade do ensino de História e de Geografia do Brasil terem sofrido alguns percalços até a efetiva implantação, visto que a legislação previa a obrigatoriedade, mas não existiam professores habilitados para tanto. Essas matérias podem propiciar uma nova pesquisa, nos mesmos moldes do ensino da Língua Portuguesa.

Não obstante a existência das muitas escolas elementares públicas e privadas subsidiadas no estado de São Paulo, não se pode afirmar que a maioria das crianças em idade escolar, estrangeiras ou filhas de estrangeiros, tenham frequentado os bancos escolares nesses anos estudados. Constatou-se, entretanto, que muitos peninsulares e filhos de peninsulares estiveram presentes nas salas de aulas das escolas elementares públicas da capital, a partir da análise das listas de chamadas de algumas dessas escolas,

de modo que não se pode afirmar que existia a plena aprendizagem da Língua Portuguesa, apesar da legislação que a impunha e da insistência no discurso dos inspetores escolares. 


\section{Referências}

ALVIM, Zuleika. Brava gente! os italianos em São Paulo 1870-1920. São Paulo: Brasiliense, 1986.

BARBOSA, Rui. Pensamento e ação de Rui Barbosa. Brasília: Senado Federal, 1999.

BEIGUELMAN, Paula. A crise do escravismo e a grande imigração. 3. ed. São Paulo: Brasiliense, 1985.

BIONDI, Luigi. Imigração italiana e movimento operário em São Paulo: um balanço historiográfico. In: CARNEIRO, Maria Luiza T.; CROCI, Federico; FRANZINA, Emilio. (Orgs) História do trabalho e história da imigração: trabalhadores italianos e sindicatos no Brasil (séculos XIX e XX). São Paulo: EDUSP: FAPESP, 2010. p. 23-48.

BIONDI, Luigi. Entre associações étnicas e de classe. Os processos de organização política e sindical dos trabalhadores italianos na cidade de São Paulo (1890-1920). 2002, 300f. Tese (Doutorado em Filosofia) - Universidade Estadual de Campinas, Doutorado em Filosofia. Campinas, 2002.

CENNI, Franco. Italianos no Brasil: andiamo in’Merica. 3. ed. São Paulo: EDUSP, 2003.

CERTEAU, Michel de. A escrita da história. Trad. Maria Menezes. Rio de Janeiro: Forense Universitária, 2002.

COLBARI, Antonia. Familismo e ética do trabalho: o legado dos imigrantes italianos para a cultura brasileira. Revista Brasileira de História, São Paulo: ANPUH: Humanitas, n. 34, 1997.

COLUCCI, Michele \& SANFILIPPO, Matteo. Guida allo Studio dell'emigrazione italiana. Viterbo: Sette Città, 2010.

COSTA, Emília Viotti da. Da senzala à colônia. 3. ed. São Paulo: Brasiliense, 1989.

CRUZ, Heloísa de Faria. São Paulo em papel e tinta: periodismo e vida urbana 1890-1915. São Paulo: Arquivo Público do Estado de São Paulo, 2013.

DI LORENZO, Ana Lucia. Italianos em Taubaté: o núcleo colonial do Quiririm 1890/1920. 2002, 200f. Dissertação (Mestrado em História) - Universidade de São Paulo, Mestrado em História. São Paulo, 2002.

FANFULLA: II Brasile e gli italiani. Firenze: R. Bemporad \& Figlio, 1906.

FAUSTO, Boris. Historiografia da imigração para São Paulo. São Paulo: Sumaré: FAPESP, 1991.

FERLINI, Vera Lucia Amaral \& FILLIPINI, Elizabeth. Os núcleos coloniais em perspectiva historiográfica. Revista Brasileira de História, São Paulo, v. 13, n. 25/26, p. 121-132, set. 92/ago. 93 . 
FRANZINA, Emílio. Mérica! Mérica! emigrazione e colonizzazione nelle lettere dei contadini veneti in America Latina: 1876-1902. Milano: Feltrinelli, 1979.

FRANZINA, Emílio. A grande emigração: o êxodo dos italianos do Vêneto para o Brasil. Trad. Edilene Toledo e Luigi Biondi. Campinas/SP: Editora da UNICAMP, 2006.

GABRIEL, Maria Cristina. Além das fronteiras do colonato. o ajustamento da coletividade italiana à sociedade local campineira durante a grande imigração: 1886-1920. 1995, $200 f$. Dissertação (Mestrado em História) - Universidade Estadual de Campinas, Mestrado em História. Campinas, 1995.

GATTAI, Zélia. Anarquistas, graças a Deus. 15. ed. Rio de Janeiro: Record, 1977.

GONÇALVES, Paulo. A cidade de São Paulo: um entreposto de braços para a lavoura cafeeira. Revista Cordis: Revista Eletrônica de História Social da Cidade, n. 2, jan./jun. 2009. Disponível em: <www.pucsp.br/revistacordis>. Acesso 20/01/2015.

HALL, Michael. Entre a etnicidade e a classe em São Paulo. In: CARNEIRO, Maria Luiza Tucci; CROCI, Federico; FRANZINA, Emilio. (Orgs) História do trabalho e história da imigração: trabalhadores italianos e sindicatos no Brasil (séculos XIX e XX). São Paulo: EDUSP: FAPESP, 2010. p. $49-64$.

HUTTER, Lucy Maffei. Imigração italiana em São Paulo (1880-1889): os primeiros contactos do imigrante com o Brasil. São Paulo: EDUSP, 1972.

HUTTER, Lucy Maffei. Imigração italiana em São Paulo de 1902 a 1914: o processo imigratório. São Paulo: EDUSP, 1986.

IANNI, Constantino. Homens sem paz: os conflitos e os bastidores da emigração italiana. Rio de Janeiro: Civilização Brasileira, 1972.

LANNA, Ana Lucia. Aquém e além mar: imigrantes e cidades. Varia História, Belo Horizonte, v. 28, n. 48, p. 871-887, jul./dez. 2012.

MARTINS, Ana Luiza. História do café. São Paulo: Contexto, 2008.

MARTINS, José de Souza. A imigração e a crise do Brasil agrário. São Paulo: Pioneira, 1973.

MATOS, Maria Izilda Santos de; MENEZES, Lená de; GOMES, Edgar da Sá; PEREIRA, Syrléa. (Orgs). Italianos no Brasil: partidas, chegadas e heranças. Rio de Janeiro: UERJ/LABIMI, 2013.

MIMESSE, Eliane. A educação e os imigrantes italianos: da escola de primeiras letras ao grupo escolar. 2. ed. São Paulo: Iglu, 2010.

MONBEIG, Pierre. Pioneiros e fazendeiros de São Paulo. São Paulo: Polis, 1984.

PAIVA, Odair; MOURA, Soraya. Hospedaria de imigrantes de São Paulo. São Paulo: Paz e Terra, 2008. 
PEREIRA, Robson. Washington Luís na administração de São Paulo (1914-1919). São Paulo: Editora da UNESP, 2010.

PETRONE, Maria Tereza Schorer. Imigração. In: HOLANDA, Sérgio Buarque de (Org.) História geral da civilização brasileira. São Paulo: DIFEL, 1985.

ROSSI, Anicleide. O quintal da fábrica. 1991, 20of. Dissertação (Mestrado em História) Universidade Estadual de Campinas, Mestrado em História. Campinas, 1991.

SALVETTI, Patrizia. Immagine nazionale ed emigrazione nella Società "Dante Alighieri”. Roma: Bonacci, 1995.

SÃO PAULO. Annuarios do ensino do Estado de São Paulo. Publicação organisada pela Inspectoria Geral do Ensino por ordem do Governo do Estado. São Paulo: Typ. Siqueira \& C.,1907 a 1914 .

SILVEIRA, Marcel. Imigração italiana em Limeira - São Paulo: terra, política e instrução escolas. Campinas, 2007. 200f. Dissertação (Mestrado em Educação) - Universidade Estadual de Campinas, Mestrado em Educação. Campinas, 2007.

SOUZA, Rosa Fátima de. Alicerces da pátria: história da escola primária no Estado de São Paulo (1890-1976). Campinas/SP: Mercado de Letras, 2009.

STOLCKE, Verena. Cafeicultura: homens, mulheres e capital 1850-1980. São Paulo: Brasiliense, 1986.

TOLEDO, Edilene. O sindicalismo revolucionário em São Paulo e na Itália: circulação de ideias e experiências uma militância sindical transnacional entre 1890 e o fascismo. 2002, 40of. Tese (Doutorado em História) - Universidade Estadual de Campinas, Doutorado em História. Campinas, UNICAMP, 2002.

TRENTO, Angelo. Organização operária e organização do tempo livre. In: CARNEIRO, Maria Luiza Tucci; CROCI, Federico; FRANZINA, Emilio. (Orgs.) História do trabalho e história da imigração: trabalhadores italianos e sindicatos no Brasil (séculos XIX e XX). São Paulo: EDUSP: FAPESP, 2010. p. 233- 266.

TRENTO, Angelo. Brasile. In: BEVILACQUA, Piero, DE CLEMENTI; Andreina; FRANZINA, Emilio. Storia dell' emigrazione italiana: arrivi. Roma: Donzelli, 2002, v.2. p. 3- 23.

Universidade do Estado de Santa Catarina - UDESC Programa de Pós-Graduação em Educação - PPGE Revista Linhas

Volume 16 - Número 32 - Ano 2015 revistalinhas@gmail.com 